\title{
Defining the Root Cause of Jakarta MBA Students' Complaint Using TQM Model of Academic Excellence
}

\author{
Sri Wijaya Salam ${ }^{\mathrm{a}, *}$, Karta Negara Salam ${ }^{\mathrm{b}}$ \\ ${ }^{a}$ Institut Teknologi Bandung \\ ${ }^{b}$ Institut Bisnis $\mathcal{E}$ Keuangan Nitro
}

\begin{abstract}
In the competitive world of education, many universities are competing to improve the quality of education services, employee performance, and produce graduates with integrity and professional skills. One of them is SBM ITB Jakarta. The purpose of this study was to determine the root causes of the quality of MBA ITB Jakarta services by using a qualitative approach and "5C TQM of academic excellence" model as a guide to improve the quality of education services. While for the technique of collecting data and analyzing qualitative data using interviews with respondents, the respondents in the study were university staff, lecturers, SBM ITB Jakarta management, and students. The results of the study concluded that there absence of such a clear role from every unit involved (in this case, SBM ITB Jakarta staff, lecturers, and management) as the root cause of student complaints related to the service quality of SBM ITB Jakarta. Miscommunication and misperception cannot be avoided because every unit has different perceptions and expectations toward each other.
\end{abstract}

\section{Keywords:}

TQM model, MBA students, academic, excellence

\section{INTRODUCTION}

Universities, as one of the educational service providers, are responsible for fulfilling government expectations in producing human resources that can compete with the global market. The need of management experts has also been increasing as a result of the implementation of Indonesia's economic development strategy, the stronger interdependent between technology and management, the importance of innovation and entrepreneurial spirit, and the importance of having ethical entrepreneurs and social responsibility.

Many excellent universities are competing to offer only the best educational service quality to their prospective students. Especially since the emphasis on quality service has been increasing over all types of business, and higher education institutions have been no exceptions in this regard. SBM Itself is considered a newcomer since it has only established in 2003 in Bandung and 2007 in Jakarta.

\footnotetext{
${ }^{*}$ Author in correspondence:

Email address: cess479@yahoo.com (Sri Wijaya Salam), kartanegara@nitromks .ac.id (Karta Negara Salam)

ISSN: 2549-3221 (Print) 2549-323X (Online)

DOI: $10.26487 /$ hebr.v3i2.2009
}

Through this paper, the research is conducted to help SBM ITB in particularly SBM ITB Jakarta to evaluate its service quality from this very early year to be able to compete with other prominent incumbents that already well known and have good reputations so that SBM ITB could emerge to be the best of business school in Indonesia.

Being endorsed by SWA as the best business school in Indonesia 2009 offers an excellent opportunity to increase the reputation of SBM ITB. At the same time, it offers a challenge for SBM ITB to work harder to keep building its reputation, since logically there is no other way from "top" but to go "down" and the fact that the room for improvement in service quality in particularly SBM ITB Jakarta is still considered significant.

The research question will be based on problem identification. On the one hand, SBM ITB has been awarded as the "best" business school, yet on the other hand, the word of "the best" has not yet felt by students concerning the service quality of SBM ITB Jakarta.

Therefore the research question will be based on; "why do students still feel inadequacy toward service quality of SBM ITB Jakarta?". This is based on the assumption that there is no perception mistake from the students' side toward service quality of SBM ITB Jakarta as a reason why the Parasuraman method is not in line with this study.

The objective of this paper is to define the root cause of 
MBA ITB Jakarta's service quality using a combination of qualitative approach and the "5C TQM academic excellence" model developed by Rajdeep and Dinesh 2010 that serves as a guideline in improving the quality service of education.

\section{LITERATURE REVIEW}

\subsection{Reputation in Educational Institution}

Two elements of internal and external shareholder groups affecting and affected by the school's reputation. They have a direct effect on reputation's construction, perseverance, and strength in educational institutions. Therefore it is possible to classify administrators, teachers, students, officers, and other service members as internal shareholders. Internal shareholders are the most critical group that affects school reputation; in other words, the corporate identity. Since they are in direct contact with customers meaning external shareholders, their attitudes and behavior have an important affected on the corporate reputation (Turgut 2008).

Although students are perceived as external customers benefiting from the school's education-instruction service, however, they affect and are affected by the school's reputation as much as administrators, teachers, and other staff by living in some environment with school employees for the academic year. Therefore it is more appropriate to evaluate students in private shareholder groups instead of outside customers group (Turgut 2008).

\subsection{Reputation and Service Quality}

These elements can be analyzed in seven dimensions, which are quality of training, quality of management, financial soundness, workplace environment, emotional appeal, social responsibility, and corporate ethics. One of the components is staff and student's pleasure that relates to service quality as it was considered as a factor that may influence the satisfaction of the customers or in this case, are students. Subsequently, measurement and evaluation of students' perceptions of service quality are precious (Rajdeep and Dinesh 2010).

\subsection{Education Service Quality}

Service quality is defined from users' perspective as consistently meeting or exceeding customer expectations, while the perceived service quality is defined as "a worldwide judgment, or attitude, relating to the superiority of the service"(Kwek et al. 2010). Despite there is no consensus in the extant literature about the development and definition of the determinants of the students' perceived service quality in higher education, the concept of what dimensions constitute quality in the area of higher education (Rajdeep and Dinesh 2010).

\subsection{SERVQUAL}

There are five key dimensions of the SERVQUAL model in which can be used by consumers to evaluate the perception of the perceived service quality. These dimensions include reliability, assurance, tangibles, responsiveness, and empathy (Lovelock and Wirtz 2004) : Gap1: Customers' expectations versus management perceptions. Gap2: Management perceptions versus service specifications. Gap3: Service specifications versus service delivery. Gap4: Service delivery versus external communication. Gap5: The discrepancy between customer expectations and their perceptions of the service delivered. Gap6: The discrepancy between customer expectations and employees' perceptions. Gap7: The discrepancy between employee's perceptions and management perceptions.

\subsection{Quality Management}

It is vital to note that the key success factor of any of these programs depends on how well a specific quality improvement program is integrated with the overall business strategy. There has been exciting research developed that proposed a TQM Model with five variables that measure different dimensions of service quality in an instrument of higher learning, and they suggest that these variables will increase student satisfaction; 1) Commitment of Top Management, 2) Course Delivery, 3) Campus facility, 4) Courtesy, and 5) Customer feedback and improvement(Lovelock and Wirtz 2004).

This model is beneficial because not only it identifies the critical quality dimensions of TQM in the specific educational environment but also serves as a guiding principle for the universities toward academic excellence. Hence, this $5 \mathrm{C}$ model is considered very relevant to the purpose of this paper to study the service quality of SBM ITB Jakarta as one of the educational institutions.

\section{METHODOLOGY}

\subsection{Approach}

The purpose of this paper is to find out the root cause of the students' complaints; then, in-depth interviews are an effective method of obtaining qualitative information because they provide great detail and give insight into what individuals think.

The researcher can observe the respondent's body language that represents emotion and expression. Qualitative researchers close enough to the people or situation under study, so it is possible for depth and a detailed understanding of the things going on. The number of respondents is not the case, but the potential of each respondent is the case to provide a better theoretical understanding of the aspects being studied. As the researcher is part of the students, it fulfills one of the requirements of the qualitative researcher is to participate in the observation of the related study.

\subsection{Data Sources}

There are two types of data used in this research; those data are primary and secondary. Primary data sources are individuals and focus groups, and the secondary data source is company background, rules that are gathered from organizations' documents. 


\subsection{Data Collection}

\section{Mechanism}

The primary data source is the respondents, and the interviews are mostly held in SBM Jakarta, the most strategic place to meet the respondents like students, staff, lecturers, and management. Language selection is essential, as not to hinder the interviewee from explaining and interviewer from capturing the things that happened. For this reason, the Indonesian language is used in interviews with all of the respondents. The researcher records information using a tape recorder and handwriting for further input in developing this research. In doing an interview, the researcher will not lock the respondents with a rigid order of questions and with specific wording as this flexible approach allows interviewee responses to guide the interaction and helps shape the order and structure of the interview.

\section{Background of Respondents}

For the simplified qualitative method, the respondents consist of students who are still studying and registered as students at SBM Jakarta. Correspondents' profile is divided into four different groups based on the status of students, staff, lecturers, and management.

\subsection{Data Analysis}

\section{Research Questions}

The variables that are used in this research are based on the 5c model by Rajdeep and Dinesh 2010; they are; course delivery, campus facility, and courtesy. Course delivery is broken down into two parts, which are "lecturers" and "material." Courtesy is represented by the word "staff." Campus facility represents physical and tangible facilities like library, books, classroom, canteen, whereas access to the only system is represented by a separate variable called "system." Adjustment on variables used in this case is only the matter of providing more excellent details for both research and respondents on identifying issues related to the service quality of SBM Jakarta.

\section{Students Interview}

The questions for students are summarized in Table 1.

\section{Staffs, Lecturers, and Managements' Interview}

All the issues identified from students' points of view are to be proposed to staff, lecturers, and management to gain an overall understanding of the situation in SBM Jakarta. An in-depth interview is used in this process to reveal the root cause of the problems; hence, a recommendation can be proposed accordingly for service quality improvement in SBM ITB Jakarta.

"What do staff and management face the problems in SBM Jakarta related to service quality"? It is asked, and the use of follow-up questions, often referred to as probes, is also used here to gain a more excellent deal of information from the respondents (Agusta 2009).
Table 1: Research Questions and Objectives

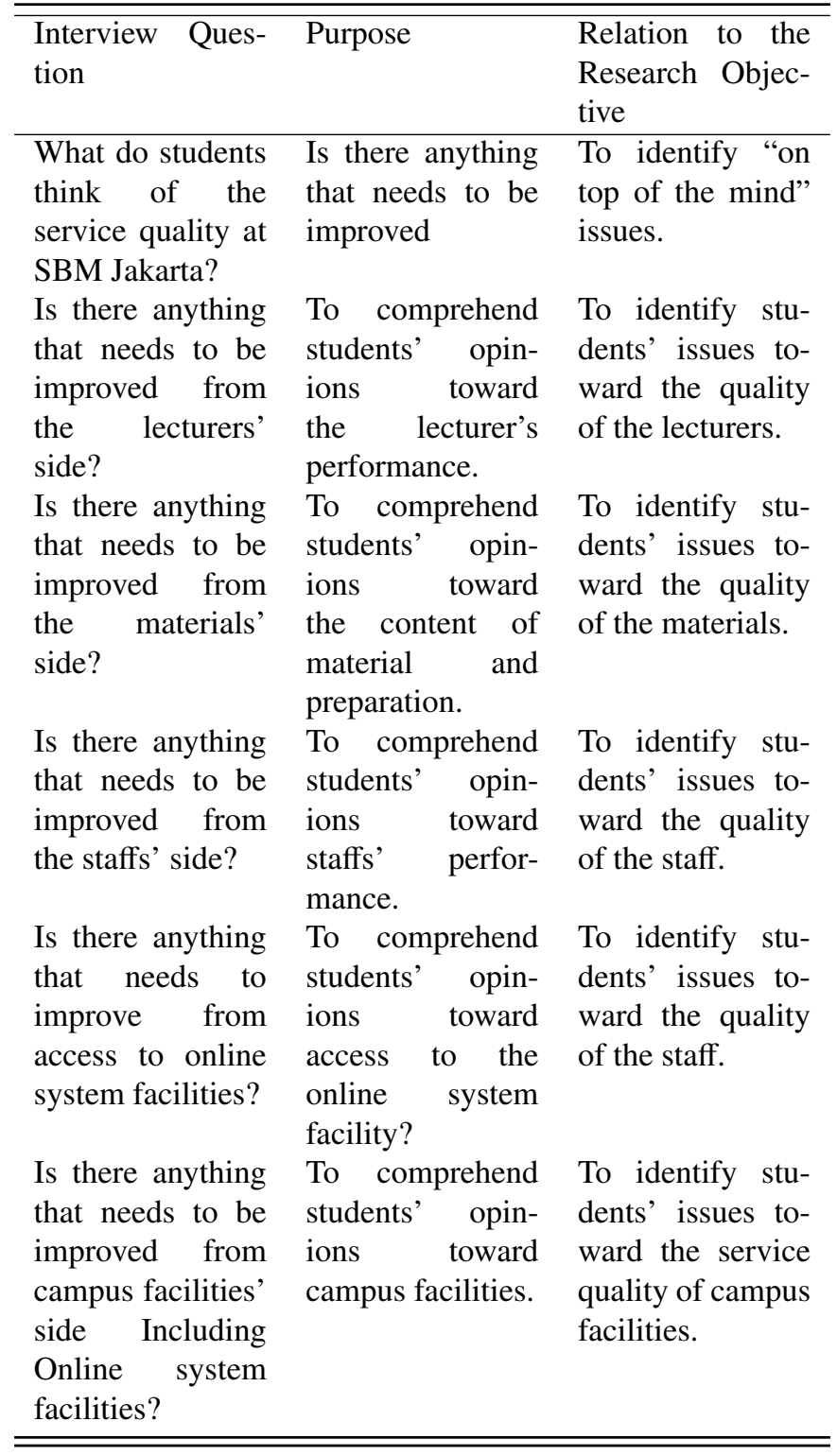

\section{Steps in Processing Information}

At this stage, all the data (issues) collected is then summarized, codified, keywords are identified, and finally, creating a cluster from each of the variables. Data reduction is a form of analysis that sharpens, classify, directed, discard the unnecessary, and organize data in such a way that conclusions can be drawn.

The presentation of data is used here where the collection of information is compiled, giving the possibility of conclusions withdrawal and taking action accordingly (Agusta 2009). In the end, the process produces a list of different kinds of issues. The list of issues is then proposed to staff, lecturers, and management of SBM ITB Jakarta to find out what are the challenges they are facing in delivering an excellent quality service. 


\section{PROBLEM ANALYSIS}

\subsection{Problem Description}

The problem between Students and Lecturers Implementing the case teaching method with a combination of practitioners has been one of the reasons for students to choose this program. Such expectations drive students' need toward more sharing experience with practitioners and field trip programs that are at the moment still considered inadequate. The same expectation related $\mathrm{s}$ to the role of practitioners that should be more towards sharing experience than on theoretical explanations.

Sharing experience is not only expected from practitioners but also lecturers. Lecturers are expected to have enough industrial background so that sharing experience can be more optimal, especially given the fact that lecturers' composition is more significant than the practitioners. As a consequence, this situation might present a challenge for some lecturers who might not have enough industrial background yet.

Finally, expectations from students toward some lecturers associated with teaching activity need also to be considered by the study program. Some of the lecturers are expected to be able to deliver the material in a more exciting way both from the content side and from the emotional engagement side.

\section{Problem between Students and Material}

The impact is quite significant as it relates to the quality of the program as a whole. This situation cannot be underestimated because not only can it lead to another problem but can also cumulatively create a bigger problem if not handled properly, as below;

This late module has made some students come to the class without adequate preparation. The module itself under normal situation is already hard to read, not to mention too many assignments that can force some students to do them in the class during lecturing time or group presentations. Additional material outside the module plus late cases from the lectures and guest lecturers are just overwhelming for some students to cope with. Finally, lack of diversity in terms of students' industrial background is another case that needs attention from the study programs because sharing experience as part of the MBA program can only be optimally achieved if the diversification itself is adequate.

\section{The problem between Students and Staffs}

One of the problems associated with staff is related to inconsistency in schedule arrangements. In reality, it is often found that students need to come to the class every single week of the month, even for only having exams in between the lecturing weeks. Seemingly, the part of having exams outside lecturing time was either not communicated or anticipated by the administrators.

They are socializing new procedures that are often carried out by calling students one by one considered not only inefficient but also ineffective. One of the examples of this is where new online registration was implemented not long time ago. Despite the guidance given through email, the staff insisted on calling the student one by one to instruct by phone. However, some students who did not want to be disturbed insisted on trying on their own based on the instruction given. What happened was that for those people who tried it on their own mostly made mistakes and they had to make a correction and redo it again with staff guidance on the other side of the line. This situation not only had given hard times to students but also the staff on the other hand.

\section{The problem between Student and Online System}

Being famous for its technology school as what ITB stands for has not been reflected well from the online system facility that is still considered limited. Despite the on-going improvement on some of the online systems, it cannot be optimally utilized yet, and this presents problems automatically. For example, the website that is supposed to provide materials to be accessed by students from a distance has occasionally led to disappointment for several reasons. The reason is that the content of the material is incomplete, and the other reason is that the website itself cannot be opened anytime. Unstable internet connection is one of the most prevalent problems that also require proper management from SBM ITB Jakarta, especially with the growing number of students.

\section{The problem between Student and Campus Facility}

For students, campus facilities might not be seen as necessary as regular students. It is very seldom for executive students to spend time around campus, as the nature of executive students is mainly busy professionals. However, this should not be an excuse for not providing students with better access to some basic needs like adequate book supplies and a proper library environment. Among the other problems associated with campus facility, catering is another problem that has also persistently existed from time to time that needs proper attention from SBM ITB Jakarta as well.

\subsection{Problem Discussions}

\section{Staff Problem Discussion}

Based on the problem discussion, it shows that staff is still struggling with a situation where they have to deliver a-student tailored need approach under the limited system. The system that covers human resource development, automation, and clear roles and commitment, from other units involved like lecturers, management at SBM Jakarta, and SBM Bandung.

\section{Lecturers Problem Discussion}

Based on the problem discussion, it shows that different perceptions exist among the lecturers; everyone has their standard in teaching, grading, preparing material that has not been well communicated to students, staff, and management. In other words, lecturers are still unsure of what their roles are in teaching an MBA Jakarta program. The absence of adequate guidelines from the management in providing a clear set of standards, adequate training, and control system is considered responsible in this case. 
Managements Problem Discussion

Based on the interview with the management of SBM ITB Jakarta, it is identified that;

1. Some of the problems are already well acknowledged by the management and considered as useful recommendations for service quality improvement, that is related to the following;

- Additional field trip and practitioner to invite.

- It has limited online access that consists of access to website content, library system, internet connection.

- A limited campus that consists of book supplies, library room, and location.

- Dependency toward building management, toward the class facility and catering.

- Indonesia's business case development.

- Student diversification in terms of industrial background.

2. The management also shares some other problems that already identified by staff and lecturer;

- Delayed module distribution that has been partly contributed by SBM ITB Bandung's role in issuing the lecturer appointment letter.

- Commitment is needed from Support staff, lecturer, and management (SBM ITB Bandung) to solve miscommunication issues, delayed module distribution, and socialization issues.

- Unstandardized grading system participation.

- The rest of the problems are associated with unclear roles and expectations from each of the internal shareholders that covers; staff, lectures, management, and the students.

This particular problem is linked to the same situations faced by lecturers and staff, where unclear roles are also a problem that leads the researcher to the next stage of finding the root cause of the students' complaint.

\subsection{Finding the Root Cause}

Among all the problems perceived by the management, defining clear roles is the most critical problem that needs to be solved. The most significant percentage of the identified problem is mostly as a result of unclear roles and expectations toward each of the internal shareholders that do not only involve staff, lecturers, management, but also students. The result shows that each of the internal shareholders has their roles that have not been communicated toward each other as a consequence, miscommunications are likely to take place as in the case of SBM ITB Jakarta. In further, the absence of clear roles has also been considered as the trigger to the problems faced by staffs, lecturers that require proper attention from the management of
SBM ITB as a whole, which does not wholly rest to the hand of SBM ITB Jakarta but also rests in the hand of SBM ITB Bandung since most of the policies and decision making are still made centrally.

\section{CONCLUSION}

Being awarded bySWAA magazine as number one in achieving the highest rating by a factor of quality and reputation as the Best BusinessSchools2009, is not a reason to be complacent. SBM ITB still has many weaknesses to cover, and room for improvement is still huge. Problems perceived by students is a reflection of internal problems in SBM ITB Jakarta that covers staffs, lecturers, students, and management. From the staffs' side, they are still struggling with a situation where they have to deliver a-student tailored need approach under the limited system. The system covers human resource development, automation, clear roles, and commitment from every unit involved. From the lecturers' side, there have not been clear roles of what they should do and what is expected from them to teach in an MBA SBM ITB. From the students' side, there have not been clear roles of what they should do and what is expected from them to be part of an MBA student at SBM ITB Jakarta. Finally, the unclear roles from each of the internal shareholders have resulted from the absence of clear roles between SBM ITB Bandung and SBM Jakarta to anticipate this matter.

Based on this illustration, miscommunication, and misperception are inevitable since every shareholder involved has different perceptions and expectations toward each other. Finally, all this problem discussion has led the researcher to the conclusion that the absence of such clear roles from every unit involved that covers staff, lectures, and SBM ITB Management as the root cause of the students' complaint in association with the service quality of SBM ITB Jakarta. It is important to note that although this paper is limited to the area SBM Jakarta, yet some of the problems have indicated the association with SBM ITB Bandung As a consequence, further research is needed that shall include the SBM ITB Bandung side to gain an overall understanding of the real situation faced by SBM ITB Jakarta.

\section{References}

Agusta, Ivanovich (2009). "Teknik Pengumpulan dan Analisis Data Kualitatif". URL: http : / ivanagusta.files . wordpress . com/2009/04/ivanpengumpulan-analisis-data-kualitatif .pdf.

Kwek, Choon Ling, Teck Chai Lau, and Hoi Piew Tan (2010). "Education Quality Process Model and Its Influence on Students' Perceived Service Quality". In: International Journal of Business and Management 5.8, pp. 154176.

Lovelock, C. and J. Wirtz (2004). Service Marketing; People, technology, Strategy. New Jersey: Prentice Hall.

Rajdeep, Singh and Khanduja Dinesh (July 2010). "SERVQUAL and Model of Service Quality Gaps: A Framework for Determining and Prioritizing Critical Factors from Faculty Perspective in Higher Education". In: International Journal of Engineering Science and Technology 2, pp. 32973304.

Turgut, Karak (2008). "Reputation Management in Educational Organizations: Suggestion of a New Model". In: Academic Leadership: The Online Journal 6.1. URL: https://scholars.fhsu. edu/alj/vol6/iss1/17. 